\title{
Are hermaphrodites better adapted to the colonization process in trioecious populations of Salix myrsinifolia?
}

\author{
Paweł Mirski*, Emilia Brzosko \\ Institute of Biology, University of Bialystok, Ciołkowskiego 1j, 15-245 Białystok, Poland
}

\begin{abstract}
In trioecious plant populations, the role of hermaphroditism is often uncertain. We investigated the advantages of hermaphroditism in the dioecious shrub Salix myrsinifolia. The sex ratio of 30 S. myrsinifolia populations in northeastern Poland (secondary range) and Lithuania (primary range) was investigated in 2010-2011. Measures of reproductive (number of catkins, number of flowers in catkins) and vegetative traits (height, diameter, number of shoots, vitality) were taken and compared among sexual morphs. In two populations, measurements collected 14 years prior on marked individuals were used to determine the rate of changes in height, crown diameter and survivorship rates. We found trioecy mostly in the secondary part of the range with an average share of hermaphrodites reaching $21 \%$ in the trioecious populations. The sex ratio varied between populations, but tended mostly towards female domination. Several traits differed significantly among sexes. The characteristics of hermaphrodites were often intermediate between males and females and provided no evidence for the higher competitive abilities of hermaphrodites. We concluded that the possible gain of hermaphroditism in the colonization process is restricted to reproduction. We consider hermaphroditism in S. myrsinifolia as an equilibrium between the allocation of resources for growth and reproduction in unstable conditions on the margins of the range.
\end{abstract}

Keywords: subdioecy; polygamy; plant gender; size structure; sexual trimorphism; sex ratio

\section{Introduction}

Sexual dimorphism in plants is characterized not only by the production of androecia vs. gynoecia (primary sexual characters) but also by a range of other morphological differences (secondary sexual characters) among sexual morphs. Males and females can also vary in traits such as individual leaf and flower size, the number of flowers, resource allocation and many others $([1,2]$ and references therein). Moreover, both sexes can be differentially influenced by biotic conditions such as parasitism and herbivory, which affect their competitive ability [3]. The latter is especially important [4] and even considered a potential force in the evolution of separate sexes from hermaphroditism [5]. Furthermore, differences in resource allocation and reproductive morphology may drive opposite sexes to specialization in different habitats (sexual specialization) and results in the spatial segregation of sexes [6]. It is likely that the phenomenon of spatial segregation of sexes may also be a result of inter-sexual competition, which may impact plants more significantly than intra-sexual competition [7].

* Corresponding author. Email: p.mirski@uwb.edu.pl

Handling Editor: Aleksandra Samecka-Cymerman
Size dimorphism is considered to be a result of different resource allocation in sexually dimorphic plants [8]. In general, females are considered to grow less due to a greater investment in reproduction, which was especially proven for woody plants [8-11]. Other factors, such as local mate competition, geitonogamy, and pollination vectors [12,13], can also influence the benefits of sex-size relations, depending on the species. Size itself positively correlates with flower production [14], the number of offspring [15] and survival probability $[16,17]$ and therefore might serve as a good indicator of competitive abilities.

Sex-dependent resource allocation is one of the evolutionary forces through which dioecy evolves via the gynodioecy pathway [18]. Although the evolution of separate sexes in plants has many advantages [19], drawbacks to sexual systems involving hermaphrodites have been recorded in several tree genera, mostly in Salix [20] and Acer [21-23], as well as in Taxus [24], Rhamnus and Populus [25]. Why is this turnover favorable if it is a step back in the evolution of sexual systems? It appears that introducing hermaphrodite individuals to previously dioecious populations may be favored in unstable conditions, such as under skewed sex ratios [26], landscape fragmentation [27], lack of pollinators [28], significant habitat alteration [29], or when the opportunities for cross-fertilization are rare, e.g., under the 
colonization process [30]. In all of the mentioned situations (resulting in low species density or population connectivity issues), hermaphrodites increase the possibility of generative reproduction with the nearest individual of any sex providing both pollen and ovules. Moreover, allocation to both male and female functions may be profitable when pollen and seed production are limited by different resources or when the cost sharing of producing pollinator attraction is more effective for both organs together [30].

Hermaphrodites are often said to differ morphologically from unisexual individuals. Faliński [29] and Nanami et al. [31] reported that hermaphrodite individuals of woody species were significantly larger than males and females. Similarly, in an Australian herb, Wurmbea dioica, hermaphrodites were found to be significantly taller than other sexes but only in some years [32]. Moreover, Faliński [29] reported that bisexual catkins in S. myrsinifolia were significantly larger than in other sexes but showed no data confirming this observation. In Sagittaria latifolia, hermaphrodites differed from males by having larger ramets and producing more flowers [33]. In W. dioica, hermaphrodites produced significantly more flowers than males and females [34].

Because mates can be rare during colonization and the invasion of new areas, sexual systems such as asexuality and selfing may be favored, and a switch in sexual systems could be observed in the populations at the edge of a range or at the edge of an invasion. In sexually dimorphic populations under colonization or in meta-population conditions, hermaphroditism is likely to become common [34]. Selfcompatible hermaphrodites are most likely to be found in populations when species density is low and when there is a lack of pollinators. In addition, they are adaptable in resource allocation between pollen and ovules or between the perfect and pistillate/staminate number of flowers [35].

Although the theoretical explanations of hermaphroditism benefits are well discussed (i.e. $[26,28,30]$ ), they are rarely studied in the field when three sex forms of one species are involved (i.e. [33]).

Salix myrsinifolia, a boreal Eurasian species, is regularly dioecious; however, on the margins of its geographical range, it produces bisexual catkins (containing male and female flowers in various patterns of both sexes partitioning on the catkin) [29]. We refer to this state as hermaphroditism, as "plants that have both male and female function but in separate flower" [36]. Populations found on the southwestern margins of this species range often involve three sexual morphs: males, females and hermaphrodites (in the sense described above) and are referred to further as trioecious [36]. The S. myrsinifolia range in Poland expanded in the XX century [37-39] and became more numerous, which was observed recently between 1987-2003 [40]. Salix myrsinifolia appeared commonly in locations where it was rare or absent a few decades ago and was even characterized by Faliński [40] as behaving "invasive". Most probably S. myrsinifolia is under slow range expansion and vast majority of Poland can be attributed to secondary range, where species distribution increases, number of population grows and different anthropogenic habitats are being inhabited. In contrary to primary range, where species is mostly noted in riparian habitats, in Poland it is most often inhabiting waste pits, ditches along roads and abandoned grasslands [29]. The border between Poland and Lithuania approximately coincides with the border between the primary (Baltic States, Fennoscandia and Northern Asia) and secondary parts (Poland) of the geographical range of $S$. myrsinifolia.

Faliński [29] noted that hermaphrodite individuals are characterized by faster growth and larger catkins. Male parts on bisexual catkins developed before female parts. Seed germinability did not differ between females and hermaphrodites. The sex of this willow showed some lability with approximately $5 \%$ of individuals changing their sex during the study. Moreover, Faliński concluded that trioecy in this species has recently become much more frequent in Poland, which together with its spatial occurrence, suggests that hermaphroditism may be an advantage during the colonization process (particularly at the southern borders of the range).

The aim of our study was to test whether hermaphrodite individuals in S. myrsinifolia are different from males and females according to their size, reproductive potential, survival rates and range of occupied habitat conditions that might facilitate colonization of new areas. We aim to test the following hypotheses:

(i) hermaphroditism in S. myrsinifolia is biased towards greater frequency in the secondary part of their geographical range;

(ii) hermaphrodites have better reproductive potential, which is manifested by a higher number of produced catkins, longer catkins and more flowers on catkins;

(iii) hermaphrodites grow faster and attain greater size than other sexes;

(iv) hermaphrodites are less likely to be susceptible to herbivory than males (similar to other willows $[41,42]$ );

$(\boldsymbol{v})$ vitality and survival rates of hermaphrodites are greater than that of at least one of the other sexes;

(vi) trioecy is more frequent in afforested (potentially isolated from pollinators) and anthropogenic habitats (according to Faliński [29]).

\section{Material and methods}

The field study was conducted in 2010-2011 at the southwestern margin of the S. myrsinifolia range in northeastern Poland and in the main parts of the range across central Lithuania. Populations of S. myrsinifolia (considered as cluster of individuals growing in generally uniform habitat) were searched for across $560 \mathrm{~km}$ of the south-north gradient following Faliński [29] (Fig. 1). In each of the 30 populations studied, all individuals were classified to one of three sex morphs: males, females or hermaphrodites. A single individual was concerned as a shrub distinctive in: architecture of branches, sex of the catkins (male, female or mixed), uniform leave sizes, color and morphology. Nonflowering individuals were impossible to distinguish their sex and were excluded from the study.

To verify the existence of trimorphism in this species and to test Faliński's [29] assumption on the more vigorous growth and better reproductive potential of hermaphrodites, we studied the frequency and size structure of the sexual 


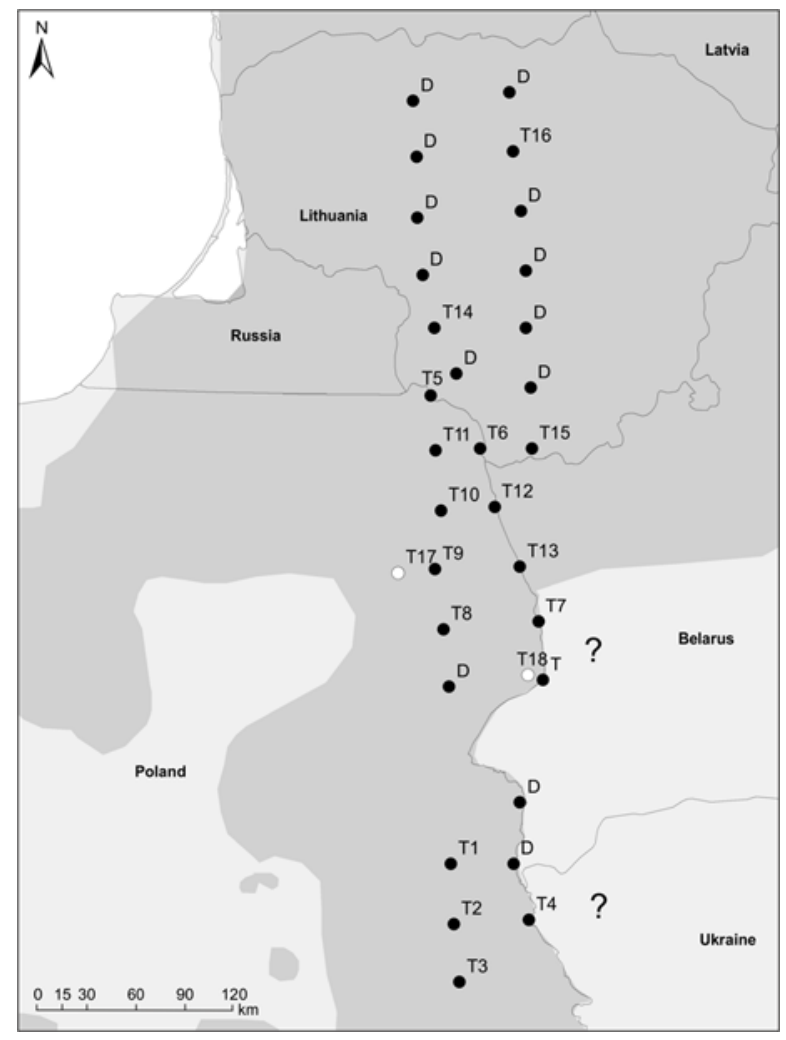

Fig. 1 Salix myrsinifolia study populations. The hatched background represents species range (according to [37-39], combined) with possible gaps (marked "?"). T - trioecious populations; $\mathrm{D}$ - dioecious populations; black dots - populations studied once in 2010 or 2011; white dots - populations where marked individuals were investigated in 1995 and 2010.

morphs of S. myrsinifolia populations. The following traits of individuals were measured in each population: height $(\mathrm{m})$, crown diameter $(\mathrm{m})$, number of shoots, number of catkins, and vitality. Height and crown diameter were measured with a scaled pole. Diameter was measured in two dimensions: first, the most broad measure, second, the perpendicular measure, and the two values were then averaged. Shoots were counted just above ground level. The number of catkins was estimated in classes as follows: less than 100, 101-1000, over 1000 . Vitality was also estimated by the percentage of dead fragments of shoots and branches and ordered in the following classes: $5 \%$ or less, $6-25 \%, 26-50 \%$, over $51 \%$. In two large populations (T17 and T18; see Fig. 1) studied previously by Faliński [29], we measured catkin traits in 30 individuals (ten males, females and hermaphrodites) at the medium flowering stage, when the catkins were fully developed, but female ones were not fruiting yet and male ones did not already decayed. From each individual, 20 catkins were randomly selected. The length of the catkin was measured, and the number of male/female flowers was counted. In addition, in one of the two populations we measured the growth rate (Biebrza Valley, Poland, T17; see Fig. 1) of 224 individuals similarly studied in 1995 by Faliński [29]. After 14 years, individuals that survived were studied as in the previous study, and the differences in height and average crown diameter were calculated for each individual, and the results were compared among sexes. In the same population, we studied the survivorship of males, females and hermaphrodites and expressed it as the rate of individuals of each sex that were still alive 14 years after marking. Additionally, to check if whole populations differed significantly from each other, we pooled the data from separate sexes and tested the possible traits (height, crown diameter, number of shoots, number of catkins, vitality) among the study populations.

To test additional environmental factors on the properties of individuals and sex ratio, population habitats were described and divided into groups: open/forested and natural/anthropogenic. We considered the S. myrsinifolia population open ( $n=19$ populations) if large trees constituted less than $25 \%$ and forested $(n=7)$ if they constituted more than $75 \%$ of the nearest surroundings ( 40 m radius). Populations in areas with afforestation between 25 and $75 \%$ were not distinct enough to include in comparisons. A population was considered natural $(n=10)$ if it was located in a natural depression or on lake edges, away from drainage ditches and roads, and together with natural or semi-natural vegetation such as alder forest, rushes, sedges or grasslands. Anthropogenic populations $(n=12)$ were located in dump pits or along drainage ditches and roads. Some populations shared both natural and anthropogenic conditions and were excluded from this analysis.

Signs of damage (debarking, shoots grazing) by large herbivores on each individual were noted to check if sexbiased herbivory occurs in this species. Then, the amount of damaged individuals among sex morphs was compared.

The comparisons of characteristics between the sexes were performed only for populations in which trioecy occurred, because the occurrence of sexual dimorphism in dioecious plants is already well known [2]. The significance of morphological differences between sexes in height, crown diameter, catkin length, growth rate and the number of flowers in catkins were tested using ANOVA. When significant differences were obtained, Tukey post-hoc tests were used to indicate the sex distinguishing from others. Differences between each studied trioecious population in the above mentioned characteristics were also done with ANOVA. Pearson and Spearman correlations were conducted for parametric and non-parametric tests, respectively. Differences in the number of catkins, viability and herbivory rate were tested with the Chi-square test assuming equal proportion results among the three sexes in expected values. Comparisons of the characteristics of individuals in open/forested and natural/anthropogenic populations were performed using a Mann-Whitney U test.

\section{Results}

\section{Sex ratio}

Sixteen out of the 30 study populations showed the trioecy phenomenon (Tab. 1), mostly (81\%) in the southern part of the studied area (outside the primary geographic range) (Fig. 1). Non-flowering individuals were noted (constituting $0-20 \%$ of populations, $8 \% \pm 10 \% S D$ on average) but excluded from further sex ratio comparisons. Hermaphrodite individuals constituted $3-42 \%$ of the populations, with an 
Tab. 1 Sex ratio in Salix myrsinifolia trioecious populations studied.

\begin{tabular}{|c|c|c|c|c|}
\hline $\begin{array}{l}\text { Population } \\
\text { number }\end{array}$ & $\begin{array}{l}\text { Number of } \\
\text { individuals }\end{array}$ & $\begin{array}{l}\text { Proportion of } \\
\text { females }\end{array}$ & $\begin{array}{c}\text { Proportion of } \\
\text { hermaphrodites }\end{array}$ & $\begin{array}{l}\text { Proportion of } \\
\text { males }\end{array}$ \\
\hline 1 & 20 & 0.35 & 0.35 & 0.30 \\
\hline 2 & 20 & 0.45 & 0.25 & 0.30 \\
\hline 3 & 9 & 0.22 & 0.11 & 0.67 \\
\hline 4 & 21 & 0.38 & 0.33 & 0.29 \\
\hline 5 & 21 & 0.55 & 0.12 & 0.53 \\
\hline 6 & 32 & 0.52 & 0.26 & 0.23 \\
\hline 7 & 12 & 0.42 & 0.42 & 0.17 \\
\hline 8 & 10 & 0.50 & 0.20 & 0.10 \\
\hline 9 & 11 & 0.64 & 0.09 & 0.18 \\
\hline 10 & 30 & 0.55 & 0.32 & 0.14 \\
\hline 11 & 37 & 0.52 & 0.12 & 0.36 \\
\hline 12 & 28 & 0.27 & 0.42 & 0.31 \\
\hline 13 & 29 & 0.38 & 0.03 & 0.59 \\
\hline 14 & 19 & 0.53 & 0.11 & 0.37 \\
\hline 15 & 30 & 0.35 & 0.15 & 0.50 \\
\hline 16 & 27 & 0.62 & 0.04 & 0.35 \\
\hline
\end{tabular}

average of $21 \% \pm 13 \% S D$. The average ratio of hermaphrodites to males was $0.89 \pm 0.79 S D$ and varied widely between 0.05 and 2.5. The ratio of hermaphrodites to females was more stable and reached an average of $0.53 \pm 0.39 \mathrm{SD}$. The ratio between males and females reached $1.02 \pm 0.83$ in all the study populations. In the trioecious populations, it reached an average of $0.91 \pm 0.71 S D$ and $1.06 \pm 0.94 S D$ in the dioecious populations, but the ratio largely varied in both groups. In the trioecious populations, females dominated over males in $68 \%$ of the populations and over hermaphrodites in $81 \%$ of the populations. In the dioecious populations, females dominated over males in $57 \%$ of the populations. Only in one population were hermaphrodites more common than males or females (Tab. 1, population No. 7). There was no correlation between the number of hermaphrodites and the number of individuals in a population $(R=-0.151, P=0.577)$ or with the male to female ratio $(R=-0.255, P=0.340)$. The number of catkins produced by each sex was distributed unevenly between the estimated quantity classes $\left(\chi_{8}^{2}=33.07\right.$, $n=330, P<0.00001)$. Most individuals produced $101-1000$ catkins, but females predominated in the lowest class (less than 100 catkins; Fig. 2a). The number of catkins produced (grouped to classes) was significantly correlated with the height (Spearman rank correlation, $R=0.239, P<0.001$ ) and crown diameter of individuals (Spearman rank correlation, $R=0.328, P<0.001)$. No such relationship was found with vitality $(R=-0.023, P=0.672)$.

The individuals of different sexes differed significantly from other sexes in the number of flowers in the catkin (ANOVA + Tukey HSD, $F=427, P<0.0001$ ) and catkin length (ANOVA + Tukey HSD, $F=100, P<0.0001$ ). Females produced the smallest number of flowers per catkin, and males produced almost twice as many flowers.
Bisexual catkins had slightly more flowers than female catkins (Fig. 3a). Each bisexual catkin contained an average of $55 \pm 37 S D$ male and $30 \pm 23 S D$ female flowers (Fig. 3b), which constitutes approximately $40 \%$ of the average number of flowers on both male and female catkins. The flowers had the highest density on male catkins $(67 \pm 26 S D$ flowers $/ \mathrm{cm})$ and the lowest density on female catkins (18 \pm 5 SD flowers/ $\mathrm{cm})$, whereas bisexual catkins reached intermediate values $(32 \pm 16 S D)$. The number of flowers of both sexes on bisexual catkins was significantly negatively correlated $(R=-0.326$, $P<0.001)$.
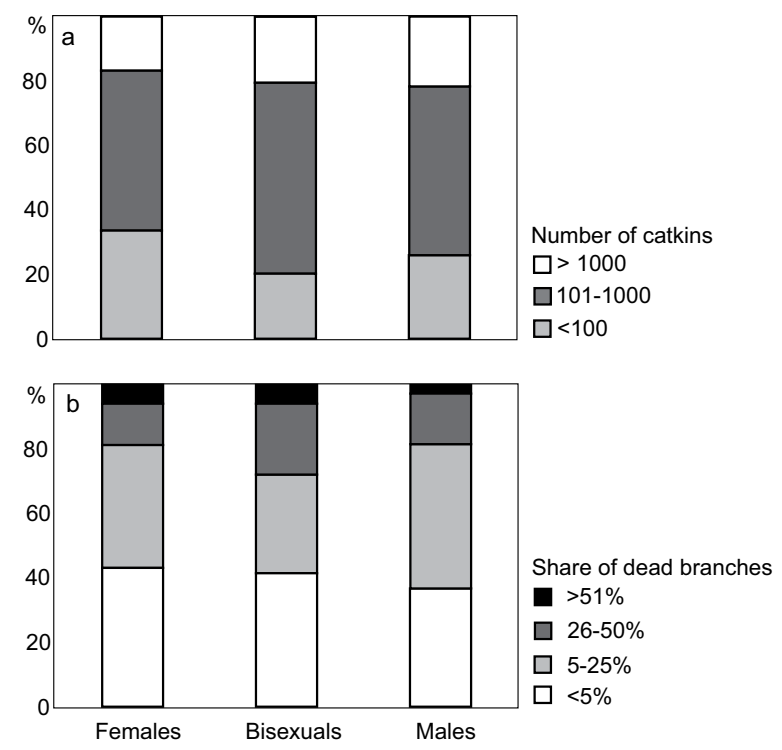

Fig. 2 Comparison of number of catkins produced (a) and vitality (b; represented by the percentage of dead branches) of each sex of Salix myrsinifolia in 16 analyzed trioecious populations. 

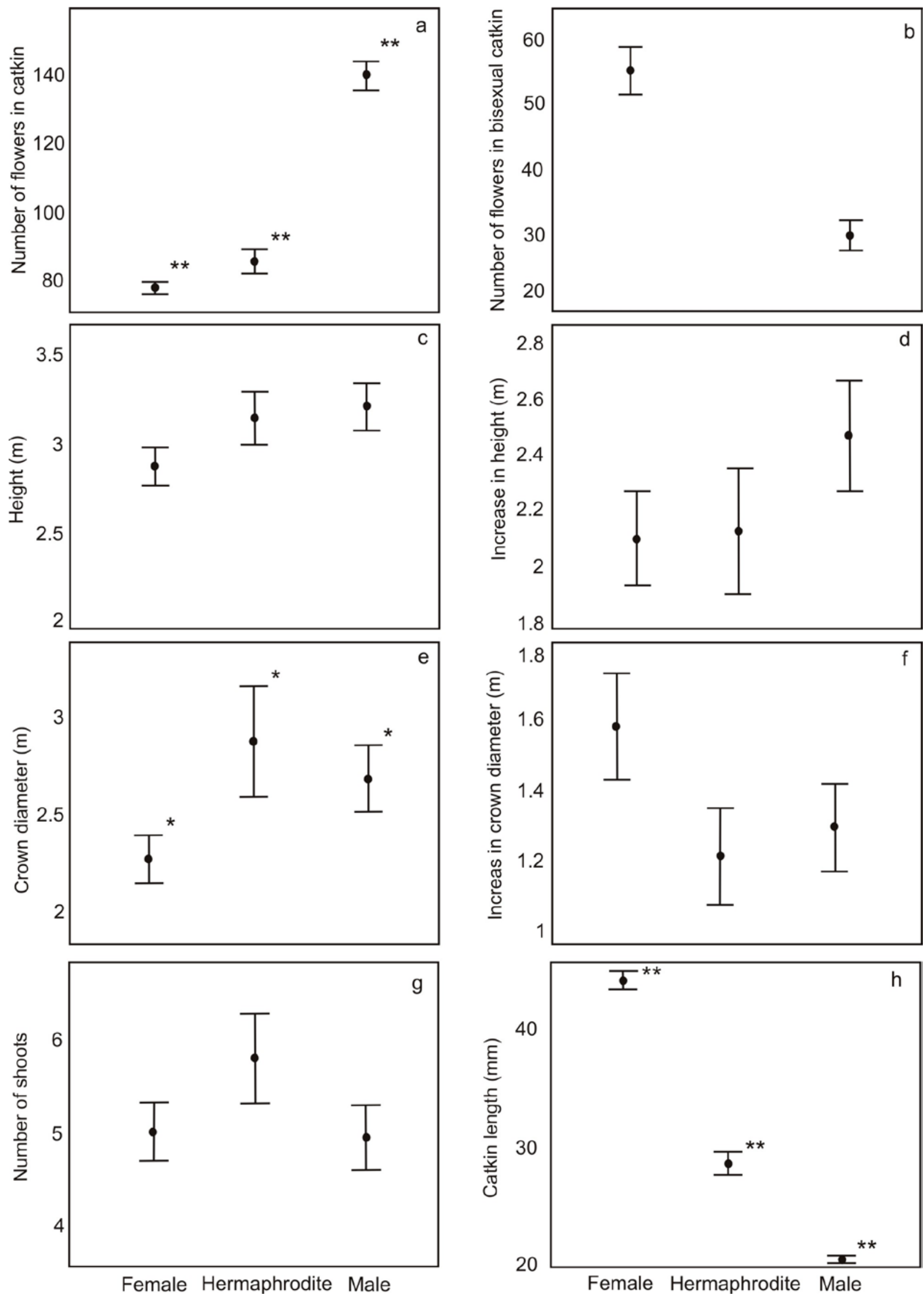

Fig. 3 Comparison of the Salix myrsinifolia sexes' mean values and standard errors of number of flowers in catkins of each sex (a) and number of male and female flowers in bisexual catkins (b), height (c) and its increase during 14 years (d), crown diameter (e) and its increase in during 14 years (f), number of shoots $(\mathbf{g})$, catkin length $(\mathbf{h})$. Results presented in plots a,b,h were measured in two populations ( $n=600$ catkins), plots $\mathbf{c , e , g , h}, \mathbf{h}$, in 16 trioecious populations $(n=356$ individuals), plots $\mathbf{d , f}$ in one population of marked individuals $(n=224)$ in the 14-year period. Bars marked with "*” show significant difference in ANOVA test in particular feature among all sex morphs. Bars marked with “**” differed significantly from each other sex morph when tested with Tukey post-hoc test. 
The survivorship of different sexes in the population of individually marked S. myrsinifolia did not differ significantly from the expected values during the 14 years of monitoring $\left(\chi_{5}^{2}=1.748, n=500, P=0.472\right.$, ) although the survival rates of females (41\%) and hermaphrodites (42\%) were smaller than that of males (48\%).

\section{Size structure}

The hermaphrodites reached intermediate values between males and females in height and growth rate (Fig. 3c,d), whereas the crown diameter and growth rate were similar to males (Fig. 3e,f). The differences were significant in crown diameter (ANOVA, $F=3.026, P<0.0001$ ) but not in height (ANOVA, $F=2.343, P=0.098$ ). However, the differences in crown diameter were not significant between each sex when tested post-hoc using Tukey's HSD. The hermaphrodites slightly dominated over males and females in the number of shoots (Fig. 3g), but the value was not significant (ANOVA, $F=1.207, P=0.3)$.

Regarding the growth rate, no significant difference was noted for height (ANOVA, $F=1.168, P=0.314$ ) or crown diameter (ANOVA, $F=1.959, P=0.150$ ), but the females showed the greatest crown diameter growth; males grew faster in terms of height (Fig. 3h). Significant differences among populations were found for all the tested variables: height (ANOVA, $F=6.298, P<0.0001$ ), crown diameter (ANOVA, $F=8.072, P<0.0001$ ) and number of shoots (ANOVA, $\left.F_{2}=4.621, P<0.0001\right)$.

\section{Impact of environmental conditions}

The frequency of trioecy in S. myrsinifolia populations differed between natural and anthropogenic habitats (MannWhitney test, $U=5500, Z=-2.441, P<0.05)$ but not between open and forested habitats (Mann-Whitney test, $U=16500$, $Z=-0.496, P=0.620)$. There was a significant difference in vitality between individuals in open and forested populations (Mann-Whitney U test, $U=6240, Z=-2.197, P<0.05$ ) and the number of catkins produced (Mann-Whitney $U$ test, $U=6647, Z=-2.375, P<0.05)$. Differences were also noted for vitality (Mann-Whitney $U$ test, $U=10804, Z=-2.08$, $P<0.05$ ) and height (Mann-Whitney $U$ test, $U=11172$, $Z=-2.234, P<0.05)$ between populations in natural and anthropogenic habitats. Individuals in the latter were taller and in better condition.

There was no difference in herbivore pressure among the sexes $\left(\chi_{2}^{2}=0.017, n=236, P=0.99\right)$. In fact, individuals were debarked very evenly: $11-12 \%$ of shrubs of each sex showed signs of herbivory. Vitality was sex biased and significantly differed from an equal distribution among the sexes $\left(\chi_{11}^{2}=34.3, n=324, P<0.001\right)$. Females were observed to be in good condition more often than expected, which was in contrast to hermaphrodites (Fig. 2b).

\section{Discussion}

Trioecy (referred to also as polygamy or subdioecy in the literature) is not an exception in Salix, contrary to the former common opinion. It was found mostly in single individuals but sometimes included the entire populations of at least 18 species [20]. We found this phenomenon common in S. myrsinifolia, especially on the borders of its geographical range. Moreover, we showed that sexual trimorphism exists in S. myrsinifolia, and the number of traits (crown diameter, number of shoots, catkin length, number of flowers in catkin) differed between the sexes. The traits of hermaphrodite individuals were mostly intermediate between males and females, and the assumed higher competitive abilities of hermaphrodites were not confirmed, based on the tested factors. However, the high percentage of hermaphrodites found in the populations in the southwestern range of distribution suggests possible advantage connected to this sexual state. No prevalence of hermaphrodites connected with faster growth, larger size or vitality was found in this species, contrary to the opinion of Faliński [29]. In S. myrsinifolia, both the height and diameter were lowest in female individuals, in which reproduction (production of both flowers and seeds) is most costly [8]. Our studies may support the hypothesis about a trade-off between growth and reproduction parameters. According to the trade-off hypothesis, female individuals are characterized by slower growth or smaller size due to the larger costs of reproduction, which is also the case in S. myrsinifolia. Leigh et al. [43] who summarized reproductive allocation in 41 dioecious species (including three subdioecious), found that in 39 of the species, the reproductive allocation of females was greater than males. Similar results were brought by Obeso, who found that in 20 out 23 species (both woody and herbaceous), female investment in reproduction was significantly greater [8].

Because no similar conclusions could be derived from this study on S. myrsinifolia, the possible gain of hermaphroditism is most likely restricted to reproduction. Sex morphs in S. myrsinifolia trioecious populations differed by traits connected with reproduction: size of inflorescences and the number of flowers in catkins. Our study showed hermaphrodites to have only slightly more flowers than females. The number of female flowers in catkins was considerably smaller than that of male flowers, which is not surprising considering the higher costs of producing female flowers [44]. On average, hermaphrodites produced about $40 \%$ of the number of flowers produced by both males and females. The catkins of hermaphrodites were intermediate in size and the number of flowers between males and females; in comparison to males, the catkins were larger, and in comparison to females, they had slightly more flowers. Because inflorescences (or catkins in this case) of larger size are more often visited by pollinators [45], the advantage of catkin size (floral display) may be crucial for reproduction, especially in fragmented populations when there is a shortage of pollinators.

Floral display size (in our case expressed as catkin length and the number of flowers on catkins) is important both for pollination by insects and wind. Floral display size contributes to the attraction of pollinators $[43,46]$ in the case of both sexes, but in females it also increases the recipient area where pollen can be deposited. Thus, the size of the floral display influences both male (donors) and female (recipients) success but in a different way - in males, through the production of a higher numbers of flowers per catkin than in females; in females, through the production of larger/longer catkins. The 
intermediate values of these parameters in hermaphrodites indicate that they can be visited more often by pollinators than males, and at the same time female flowers can be fertilized. The relationship between hermaphrodites and pollination was also considered by other authors, which suggests that pollinator abundance and pollen limitation play an important role in the maintenance of trioecy [47].

As willows are mostly dioecious (but see [20]), the hermaphrodite individuals in some species were not checked for selfing. It is probable that hermaphrodites in willows are self-compatible, and large pollinators such as bees or even the common Blue Tit Cyanistes caeruleus [48] may transfer pollen grains to stigmas between flowers on the same catkin. Such a transfer is facilitated in Salix because some species are both wind and insect pollinated (e.g., [49,50]). Wind pollination is facilitated in this genus by early flowering (before leaf development) and the release of pollen into the air. Flower morphology enables wind pollination - the perianth is absent, whereas the stamens and pistils outreach the catkin [51].

The androdioecious tree Fraxinus lanuginose, previously considered self-sterile, was revealed to be capable of selfing [52]. Moreover, selfing rates were higher in populations with low male frequency. Low male frequency was, however, correlated to the low density of individuals and influenced selfing by limited cross-pollination [52]. Similarly, other woody species, such as heterodichogamous Acer mono and Juglans ailantifolia, are quite prone to selfing [53,54], although they are endowed with mechanisms to avoid selfing.

Herbivory (at least by large mammals) was not biased by sex as it could be expected from studies on other willow species $[41,42]$, therefore no clear advantage of any sex morph can be highlighted here. Also regardless of sex, individuals in populations overgrown by forest produced fewer catkins, so none of the sex morphs proved to be better resisting the light competition. Hermaphrodites showed however some habitat preference and grew more often in anthropogenic habitats, confirming the association of the ruderalisation of habitat and the incidence of trioecy in this species [29].

Although we did not find any advantage of hermaphrodites in the measured traits, it seems that their presence (sometimes with high frequency) on the margins of the geographic range is the best evidence of the benefit of this trait. Because S. myrsinifolia is mostly dioecious in central parts of the range (examination of herbarium collections

\section{Acknowledgments}

This work was supported by the Polish Ministry of Science and Higher Education (grant number NN304 335439). PM is a beneficiary of the project "Scholarships for PhD students of Podlaskie Voivodeship". The project is co-financed by the European Social Fund, Polish Government and Podlaskie Voivodeship.

We would like to thank anonymous reviewers for their valuable advice on the manuscript and to Bogdan Jaroszewicz, Director of Białowieża Geobotanical Station of Warsaw University for sharing Prof. Faliński's data on Salix myrsinifolia's sex ratio in Poland and Lithuania during the years 1995-2001.

\section{Authors' contributions}

The following declarations about authors' contributions to the research have been made: research designing, conducting field study, analyzing in [29]), the advantages concluded above are not universal and are restricted to the margins of the range. The other question is whether trioecy is a temporal phenomenon in S. myrsinifolia, connected with only some phases in population history (colonization) or whether it has become a new trait adapted to other climatic/environment conditions outside the primary geographic range. Simulated climatic changes weakly affected the differences in the traits of males and females in S. myrsinifolia [55]; thus, another sex probably did not directly result from different climatic conditions. It was most likely influenced by population demography. According to Yu and Lu [27], dioecious plants are sensitive to changes, especially in population size and structure, which can be a realistic issue in the colonization phase or under unusual conditions on the margins of the range, where populations are more fragmented and isolated. Many authors observed that individuals are often smaller and have lower rates of generative reproduction and more intense vegetative reproduction in marginal populations. In the first phase of population development, in the case when only one individual colonizes a new location (the founding individual), the production of progeny is impossible in unisexual individuals in contrast to hermaphrodites forming flowers of both sexes, which enables selfing. Thus, it seems that sex lability to hermaphroditism could be one of the important advantages of pioneer or expansive species (e.g., Acer negundo in Poland [23]). An experimental study on Silene vulgaris confirms that hermaphrodites can obtain better reproductive success than females when the population is isolated [56]. Bottlenecks acting during range expansion become a selective force for sexual systems in this scenario [57]. The presence of trioecy in the populations of S. myrsinifolia we studied may be strengthened in this way.

In conclusion, the hermaphrodites in S. myrsinifolia trioecious populations are only partly morphologically different from males or females. Contrary to our expectations, their characteristics were intermediate between males and females.

The basic evidence of their role in species expansion (the colonization of new areas) is the fact that they are present almost exclusively outside the areas of the main geographic range. It seems that the possibility to have three sex morphs could be one of the important characteristics of pioneer or expansive species. It still remains unclear whether this advantage is temporal or adaptive in a true sense.

data, writing the manuscript: PM; research designing, partly writing the manuscript, advising: EB.

\section{Competing interests}

No competing interests have been declared.

\section{References}

1. Dawson TE, Geber MA. Sexual dimorphism in physiology and morphology. In: Geber MA, Dawson TE, Delph LF, editors. Gender and sexual dimorphism in flowering plants. Berlin: Springer-Verlag; 1999. p. 176-215. http://dx.doi.org/10.1007/978-3-662-03908-3_7

2. Barrett SCH, Hough J. Sexual dimorphism in flowering plants. J Exp Bot. 2013;64:67-82. http://dx.doi.org/10.1093/jxb/ers308

3. Ågren J, Danell K, Elmqvist T, Ericson L, Hjältén J. Sexual 
dimorphism and biotic interactions. In: Geber MA, Dawson TE, Delph LF, editors. Gender and sexual dimorphism in flowering plants. Berlin: Springer-Verlag; 1999. p. 217-246. http://dx.doi. org/10.1007/978-3-662-03908-3_8

4. Cornelissen T, Stirling P. Sex-biased herbivory: a metaanalysis of the effects of gender on plant-herbivore interactions. Oikos. 2005;111:488-500. http://dx.doi.org/10.1111/j.1600-0706.2005.14075.x

5. Ashman TL. The role of herbivores in the evolution of separate sexes from hermaphroditism. Ecology. 2002;83:1175-1184. http://dx.doi. org/10.2307/3071932

6. Bierzychudek P, Eckhart V. Spatial segregation of the sexes in dioecious plants. Am Nat. 1988;132:34-43. http://dx.doi.org/10.1086/284836

7. Mercer CA, Eppley SM. Inter-sexual competition in a dioecious grass. Oecologia. 2010;164:657-664. http://dx.doi.org/10.1007/ s00442-010-1675-4

8. Obeso JR. The costs of reproduction in plants. New Phytol. 2002;155:321-348. http://dx.doi.org/10.1046/j.1469-8137.2002.00477.x

9. Freeman DC, Harper KT, Charnov EL. Sex change in plants: old and new observations and new hypotheses. Oecologia. 1980;47:222-232. http://dx.doi.org/10.1007/BF00346825

10. Bierzychudek P. Determinants of gender in Jack-in-the-pulpit: the influence of plant size and reproductive history. Oecologia. 1984;65:14-18. http://dx.doi.org/10.1007/BF00384456

11. Iszkuło G, Jasińska AK, Romo A, Tomaszewski D, Szmyt J. The greater growth rate of male over female of the dioecious tree Juniperus thurifera only in worse habitat conditions. Dendrobiology. 2011;66:15-24.

12. Klinkhamer PGL, de Jong TJ, Metz H. Sex and size in cosexual plants. Trends Ecol Evol. 1997;12:260-265. http://dx.doi.org/10.1016/ S0169-5347(97)01078-1

13. Lloyd DG, Bawa KS. Modification of gender of seed plants in varying conditions. Evol Biol. 1984;17:255-338. http://dx.doi. org/10.1007/978-1-4615-6974-9_6

14. Weiner J, Thomas SC. Size variability and competition in plant monocultures. Oikos. 1986;47:211-222. http://dx.doi.org/10.2307/3566048

15. Leverich WJ, Levin DA. Age-specific survivorship and reproduction in Phlox drummondii. Am Nat. 1979;113:881-903. http://dx.doi. org/10.1086/283443

16. Watkinson AR, Lonsdale WM, Firbank LG. A neighbourhood approach to self-thinning. Oecologia. 1983;56:381-384. http://dx.doi. org/10.1007/BF00379716

17. Horvitz CC, Schemske DW. Leaf herbivory and neighbourhood competition in a neotropical herb: effects on demographic fates. J Ecol. 2002;90:279-290. http://dx.doi.org/10.1046/j.1365-2745.2001.00660.x

18. Ashman TL. The evolution of separate sexes: a focus on the ecological context. In: Harder LD, Barrett SCH, editors. Ecology and evolution of flowers. Oxford: Oxford University Press; 2006. p. 204-222.

19. Bawa KS. Evolution of dioecy in flowering plants. Annu Rev Ecol Syst. 1980;11:15-39. http://dx.doi.org/10.1146/annurev.es.11.110180.000311

20. Mirski P. Exceptions from dioecy and sex lability in genus Salix. Dendrobiology. 2014;71:167-171. http://dx.doi.org/10.12657/ denbio.071.017

21. Primack RB, McCall C. Gender variation in a red maple population (Acer rubrum; Aceraceae): a seven-year study of a polygamodioecious species. Am J Bot. 1986;73:1239-1248. http://dx.doi. org/10.2307/2444057

22. Ushimaru A, Matsui K. Sex change in tree species: long-term monitoring of sex expression in Acer rufinerve. Nord J Bot. 2001;21:397-399. http://dx.doi.org/10.1111/j.1756-1051.2001.tb00785.x

23. Mędrzycki P, Kołaszewska B, Browiński P. Subdioecy in invasive populations of Acer negundo (Aceraceae) in eastern Poland. Pol Bot Stud. 2006;22:355-364.

24. Iszkuło G, Jasińska AK.Variation in sex expression in Polish and Ukrainian populations of Taxus baccata L. Dendrobiology. 2004;52:29-32.

25. Rottenberg A. Fertility of exceptional bisexual individuals in four dioecious plant species. Sex Plant Reprod. 2000;12:219-221. http:// dx.doi.org/10.1007/s004970050003

26. Dorken ME, Pannell JR. Hermaphrodite sex allocation evolves when mating opportunities change. Curr Biol. 2009;19:514-517. http:// dx.doi.org/10.1016/j.cub.2009.01.067

27. Yu L, Lu J. Does landscape fragmentation influence sex ratio of dioecious plants? A case study of Pistacia chinensis in the Thousand-Island Lake region of China. PLoS ONE. 2011;6(8):e22903. http://dx.doi. org/10.1371/journal.pone.0022903

28. Ehlers BK, Bataillon T. "Inconstant males" and the maintenance of labile sex expression in subdioecious plants. New Phytol. 2007;174:194211. http://dx.doi.org/10.1111/j.1469-8137.2007.01975.x

29. Faliński JB. Androgyny of individuals and polygamy in populations of Salix myrsinifolia Salisb. in the south-western part of its geographical range (NE-Poland). Perspect Plant Ecol Evol Syst. 1998;1:238-266. http://dx.doi.org/10.1078/1433-8319-00061

30. Charnov EL, Maynard Smith J, Bull JJ. Why be an hermaphrodite? Nature. 1976;263:125-126. http://dx.doi.org/10.1038/263125a0

31. Nanami S, Kawaguchi H, Yamakura T. Sex change towards female in dying Acer rufinerve trees. Ann Bot. 2004;93:733-740. http://dx.doi. org/10.1093/aob/mch093

32. Barrett SCH, Case AL, Peters GB. Gender modification and resource allocation in subdioecious Wurmbea dioica (Colchicaceae). J Ecol. 1999;87:123-137. http://dx.doi.org/10.1046/j.1365-2745.1999.00336.x

33. Sarkissian TS, Barrett SCH, Harder LD. Gender variation in Sagittaria latifolia (Alismataceae): is size all that matters? Ecology. 2001;82:360-373. http://dx.doi.org/10.2307/2679865

34. Pannell JR. The maintenance of gynodioecy and androdioecy in a metapopulation. Evolution. 1997;51:10-20. http://dx.doi. org/10.2307/2410955

35. Vaughton G, Ramsey M. Gender plasticity and sexual system stability in Wurmbea. Ann Bot. 2012;109:521-530. http://dx.doi.org/10.1093/ aob/mcr 163

36. Sakai AK, Weller SG. Gender and sexual dimorphism in flowering plants: a review of terminology, biogeographic patterns, ecological correlates, and phylogenetic approaches. In: Geber MA, Dawson TE, Delph LH, editors. Sexual and gender dimorphism in flowering plants. Heidelberg: Springer-Verlag; 1999. p. 1-31. http://dx.doi. org/10.1007/978-3-662-03908-3_1

37. Chmelař J, Meusel W. Die Weiden Europas. Wittenberg Lutherstadt: Die Neue Brehm - Bucherei, A Ziemsen Verlag; 1979.

38. Skvortsov AK. Willows of the USSR. Moscow: Nauka; 1968

39. Zieliński J. Salix nigricans Sm. In: Browicz K, editor. Atlas rozmieszczenia drzew i krzewów w Polsce. Warszawa: PWN; 1976. p. 13-15. (vol 20).

40. Faliński JB. Inwazje w świecie roślin: mechanizmy, zagrożenia, projekt badań. Phytocenosis. 2004;16:14

41. Danell K, Elmqvist T, Ericson L, Salomonson A. Sexuality in willows and preference by bark-eating voles: defense or not? Oikos. 1985;44:82-90. http://dx.doi.org/10.2307/3544047

42. Boecklen WJ, Price PW, Mopper S. Sex and drugs and herbivores: sex-biased herbivory in arroyo willow (Salix lasiolepis). Ecology. 1990;71:581-588. http://dx.doi.org/10.2307/1940311

43. Leigh A, Cosgrove MJ, Nicotra AB. Reproductive allocation in a gender dimorphic shrub: anomalous female investment in Gynatrix pulchella? J Ecol. 2006;94:1261-1271. http://dx.doi. org/10.1111/j.1365-2745.2006.01164.x

44. Wallace CS, Rundel PW. Sexual dimorphism and resource allocation in male and female shrubs of Simmondsia chinensis. Oecologia. 1979;44:34-39. http://dx.doi.org/10.1007/BF00346394

45. Ramsey M, Vaughton G. Sex expression and sexual dimorphism in subdioecious Wurmbea dioica (Colchicaceae). Int J Plant Sci. 2001;162:589-597. http://dx.doi.org/10.1086/320142

46. Maki M. Differences in plant size and flower production between hermaphrodites and females of two gynodioecious Chionographis (Liliaceae). Can J Bot. 1996;74:150-153. http://dx.doi.org/10.1139/b96-020 
47. Fleming T, Maurice S, Hamrick J. Geographic variation in breeding system and the evolutionary stability in trioecious cactus, Pachycereus pringlei (Cactaceae). Evol Ecol. 1998;12:279-289. http://dx.doi. org/10.1023/A:1006548132606

48. Kay QON. Nectar from willow catkins as a food source for Blue Tits. Bird Study. 1985;32:40-44. http://dx.doi.org/10.1080/00063658509476853

49. Argus GW. An experimental study of hybridization and pollination in Salix (willows). Can J Bot. 1974;52:1613-1619. http://dx.doi. org/10.1139/b74-212

50. Peeters L, Totland $\varnothing$. Wind to insect pollination ratios and floral traits in five alpine Salix species. Can J Bot. 1999;77:556-563. http://dx.doi. org/10.1139/cjb-77-4-556

51. Fisher MJ. The morphology and anatomy of the flowers of the Salicaceae 1-2. Am J Bot. 1928;15:307-394. http://dx.doi. org/10.2307/2435733

52. Ishida K, Hiura T. Mating system and population genetic structure of an androdioecious tree, Fraxinus lanuginosa Koidz. (Oleaceae) in northern Japan. Heredity. 2002;88:296-301. http://dx.doi.org/10.1038/ sj.hdy. 6800043
53. Kikuchi S, Shibata M, Tanaka M, Toshimaru H, Niyama K. Analysis of the disassortative mating pattern in a heterodichogamous plant, Acer mono Maxim. using microsatellite markers. Plant Ecol. 2009;204:43-54. http://dx.doi.org/10.1007/s11258-008-9564-1

54. Kimura MG, Goto S, Suyama Y, Matsui M, Woeste K, Seiwa K. Morphspecific mating patterns in a low-density population of a heterodichogamous tree, Juglans ailantifolia. Plant Ecol. 2012;213:1477-1487. http://dx.doi.org/10.1007/s11258-012-0105-6

55. Nybakken L, Julkunen-Tiitto R. Gender differences in Salix myrsinifolia at the pre-reproductive stage are little affected by simulated climatic change. Physiol Plant. 2013;147:465-476. http://dx.doi. org/10.1111/j.1399-3054.2012.01675.x

56. Taylor DR, Trimble S, McCauley DE. Ecological genetics of gynodioecy in Silene vulgaris: relative fitness of females and hermaphrodites during the colonization process. Evolution. 1999;53:745-751. http://dx.doi. org/10.2307/2640714

57. Pannell JR, Dorken ME. Colonisation as a common denominator in plant metapopulations and range expansions: effects on genetic diversity and sexual systems. Landsc Ecol. 2006;21:837-848. http:// dx.doi.org/10.1007/s10980-005-5389-7 